Regina Heloisa Mattei de Oliveira Maciel $^{1}$

João Bosco Feitosa dos Santos ${ }^{2}$

Rosana Lima Rodrigues ${ }^{3}$

1 Universidade de Fortaleza, Centro de Ciências da Saúde, Programa de PósGraduação em Psicologia. Fortaleza, CE, Brasil.

${ }^{2}$ Universidade Estadual do Ceará, Centro de Humanidades, Programa de Mestrado em Políticas Públicas e Sociedade. Fortaleza, CE, Brasil.

${ }^{3}$ Universidade Federal do Ceará, Programa de Pós-Graduação em Sociologia. Fortaleza, CE, Brasil.

Contato:

João Bosco Feitosa dos Santos E-mail:

bosco_feitosa@yahoo.com.br

O trabalho não é baseado em tese e não foi apresentado em reunião científica.

O texto é parte de pesquisa financiada pela Organização Panamericana de Saúde - OPAS e Ministério da Saúde/ Rede Observatório de Recursos Humanos em Saúde - ROREHS.

Os autores declaram não haver conflitos de interesses.

\section{Condições de trabalho dos trabalhadores da saúde: um enfoque sobre os técnicos e auxiliares de nível médio}

\author{
Healthcare Workers' Work Conditions: a perspective on \\ technicians and midlevel workers
}

\begin{abstract}
Resumo
Objetivo: analisar as percepções sobre as condições de trabalho do pessoal técnico de nível médio das Unidades Básicas de Saúde (UBS) de Fortaleza, Ceará. Métodos: o percurso metodológico incluiu observação de postos de trabalho e entrevistas semiestruturadas com 25 profissionais auxiliares ou técnicos administrativos, auxiliares ou técnicos em saúde bucal e auxiliares ou técnicos de enfermagem, de 12 UBS do Sistema Único de Saúde (SUS) da cidade de Fortaleza, no ano de 2012. Resultados: os resultados mostraram que as condições de trabalho e, como consequência, as condições do atendimento aos usuários são precárias tanto no que se refere à infraestrutura das unidades quanto em relação à organização das tarefas e das atividades dos técnicos. Conclusão: os custos desse trabalho, realizado em condições precárias, refletem-se sobre a saúde desses profissionais, que se mostram exaustos física e emocionalmente, além de repercutirem na precariedade da atenção à saúde dos usuários do SUS.
\end{abstract}

Palavras-chave: pessoal técnico de saúde; condições de trabalho; Unidades Básicas de Saúde; Sistema Único de Saúde.

\begin{abstract}
Objective: to analyze the perceptions on working conditions of midlevel technical staff from UBS (Basic Health Units) of Fortaleza, Ceará, Brazil. Methods: work places observation and semi structured interviews with 25 midlevel technical professionals - administrative, dental health and nursing assistants - of 12 UBS of the public health system of Fortaleza, during 2012. Results: the results showed that the working conditions and, therefore, user care, are precarious regarding both units' infrastructure and organization of the midlevel technicians' tasks and activities. Conclusion: the costs of such work, conducted in precarious conditions, are reflected on the professionals' health that reveal themselves physically and emotionally exhausted and ultimately reflect the precariousness of the Public Health System (SUS).
\end{abstract}

Keywords: allied health personnel; working conditions; health centers; public health system. 


\section{Introdução}

Os profissionais de nível técnico da área de saúde desempenham papel fundamental na constituição e no desenvolvimento do atendimento em saúde. Entretanto, suas condições de trabalho não têm sido estudadas de acordo com sua importância para o funcionamento do Sistema Único de Saúde (SUS) (VIEIRA; CHINELLI, 2013, p. 1596).

Embora o Ministério da Saúde e os governos estaduais e municipais busquem melhorar a qualidade da atenção hospitalar e ambulatorial por meio da oferta de qualificação profissional dos trabalhadores da área de enfermagem de nível médio (técnicos), ao inseri-los em uma política de valorização profissional (ALMEIDA; FERRAZ, 2008), ainda há muito que ser feito para melhorar as efetivas condições de trabalho e a precarização dos vínculos desse contingente de profissionais.

Nessa perspectiva, algumas questões serviram de pretexto para este estudo: Quais são as condições de trabalho a que estão submetidos os técnicos de saúde? Quais fatores da organização do trabalho são os mais destacados pelos técnicos das Unidades Básicas de Saúde (UBS) de Fortaleza? Quais aspectos relacionados às condições e à organização do trabalho podem repercutir na precariedade do SUS? Diante dessas indagações, este estudo focaliza as condições de trabalho ${ }^{4}$ do pessoal de nível técnico da área da saúde da cidade de Fortaleza, Ceará.

Os estudos sobre as condições e sobre a organização do trabalho no SUS mostram realidades diferentes nos diversos Estados e regiões do país. Medeiros e Rocha (2004) discutem a problemática dos modelos de administração neoliberais, largamente implantados em todos os setores econômicos, a partir dos anos de 1980, e as suas relações com as condições socioeconômicas dos trabalhadores da saúde, enfatizando, especialmente, as consequências dessa implantação na região Nordeste do país. Conforme as autoras, na medida em que as políticas neoliberais de reestruturação do trabalho compõem as diretrizes do modelo largamente adotado no gerenciamento local dos estabelecimentos de saúde no Brasil, as dificuldades enfrentadas pelos trabalhadores dentro do SUS aprofundam as desigualdades, as injustiças e a instabilidade social. Consideram como principal consequência do modelo para os trabalhadores da saúde a flexibilização da força de trabalho, a qual ocorre em função das mudanças no processo produtivo. Os trabalhadores se submetem a essas condições para garantir seus empregos. Ao fazerem isso, se submetem a perdas de direitos trabalhistas, o que pode produzir tensão e insegurança no trabalhador. No entanto, tentam compensar as perdas salariais por meio do multiemprego, o que os leva ao estresse, à fadiga e a acidentes de trabalho. Consideram ainda que a feminilização da força de trabalho em saúde conduz à dupla jornada à desigualdade salarial e à falta de lazer desses trabalhadores, na medida em que seu tempo livre é dedicado a outro emprego ou à realização de capacitação para que possam se manter no mercado de trabalho.

Sobre as condições organizacionais dos trabalhadores da saúde, Medeiros e Rocha (2004) consideram dentre os principais problemas enfrentados pelos profissionais da saúde, tanto de nível superior quanto de nível técnico: a heteronomia salarial; a jornada de trabalho diferenciada e desigual; os critérios arbitrários para ascensão funcional; a ausência de Plano de Cargos, Carreira e Salários (PCCS); a falta de avaliação de desempenho ou avaliações realizadas sem critérios explícitos; a ausência das diretrizes e princípios técnico-institucionais na contratação por clientelismo; os baixos salários; a ausência de uma política de educação continuada; a polarização nas categorias majoritárias de médicos e pessoal sem formação específica (atendentes, agentes de saúde e similares); a sobrecarga de trabalho para Devido às dificuldades gerenciais e à precariedade das condições de trabalho, os profissionais da saúde ficam sujeitos, eles próprios, a problemas de saúde. Guimarães et al. (2005) descrevem estudo realizado em um hospital universitário sobre os acidentes de trabalho, concluindo que os fatores de risco associados aos profissionais da saúde são: a divisão de tarefas insatisfatórias, a excessiva concentração de atividades, o acúmulo de tarefas e a ocupação total da carga horária durante a jornada de trabalho. Do mesmo modo que pode haver repercussões negativas na saúde do trabalhador a partir das condições de trabalho, pode haver um reflexo disso na precariedade do sistema de saúde, uma vez que os entraves ocorridos no âmbito das unidades de saúde envolvem também os usuários e o sistema como um todo.

\footnotetext{
4 Entende-se por condições de trabalho os fatores físicos, sociais e administrativos relativos ao meio em que um trabalhador exerce sua atividade profissional. Dejours (1992) diferencia condições de trabalho de organização do trabalho, sendo a primeira referente ao ambiente físico, químico e biológico, adicionado às condições de higiene, de segurança e às características antropométricas do posto de trabalho. A organização se refere à divisão do trabalho, ao conteúdo da tarefa, ao sistema hierárquico e às modalidades de comando, de relações de poder, entre outras atribuições da hierarquia institucional. Para este estudo, porém, fica estabelecido que as condições de trabalho incluem todos os aspectos fragmentados por Dejours, por compreendermos que esse termo é mais abrangente e autoexplicativo das condições objetivas e subjetivas do interior de uma instituição laboral.
} 
No Ceará, os problemas que ocorrem no SUS se tornam mais profundos na medida em que as políticas de desenvolvimento socioeconômico não têm demonstrado avanços capazes de mudar o quadro de desigualdade de forma rápida e eficiente. Apesar disso, no que se refere à implantação do Programa de Saúde da Família (PSF), hoje denominado Estratégia Saúde da Família (ESF) e Programa de Agentes Comunitários de Saúde (PACS) no SUS, o Ceará se destaca no Brasil por causa de sua política de descentralização de recursos e de incentivos aos municípios (MARQUES; MENDES, 2003).

Com relação ao pessoal técnico de nível médio, há uma preocupação crescente com a sua formação (GIL, 2005) e as suas competências, como indica o estudo de Peduzi et al. (2006). No entanto, não há uma descrição detalhada das atividades que exercem no âmbito das unidades e estudos que focalizem, especialmente, suas condições de trabalho e de saúde.

Diante da importância desses profissionais para o atendimento e para o desenvolvimento dos demais trabalhos que devem ser realizados nas UBS, incluindo tarefas de cunho burocrático, gestão dos serviços, vigilância em saúde, entre outras, é importante investigar a repercussão desse trabalho não somente para o profissional, mas para o sistema de saúde.

Na análise das condições de trabalho do pessoal técnico das UBS de Fortaleza, foram focados, entre os profissionais de nível médio dessas unidades, os técnicos administrativos ou auxiliares administrativos, técnicos em saúde bucal ou auxiliares em saúde bucal e técnicos de enfermagem ou auxiliares de enfermagem. Além disso, tencionou-se investigar as percepções desses profissionais sobre seus problemas de trabalho e de saúde relacionados ao trabalho, bem como a sua relação com a precariedade do sistema de saúde do município.

\section{Percurso metodológico}

A pesquisa de natureza quali-quantitativa utilizou, na sua aproximação ao campo, de uma metodologia inspirada nos estudos ergonômicos. Os métodos da ergonomia focalizam os postos de trabalho e as atividades ali desenvolvidas como unidade de intervenção e de análise e visam à compreensão de suas condições materiais e organizacionais, verificando sua adequação às características gerais dos trabalhadores (FALZON, 2007; WISNER, 2005).

Na coleta de dados, realizada durante o ano de 2012, foram utilizadas observações dos locais de trabalho e entrevistas com o pessoal técnico das UBS visitadas.

\section{Loci da pesquisa}

As divisões administrativas de Fortaleza e suas Unidades Básicas de Saúde (UBS)

O município de Fortaleza está dividido em seis Secretarias Executivas Regionais (SER). Essa divisão administrativa considera, dentre as suas principais variáveis, a condição sociodemográfica da cidade. No início da configuração das SER, o número de habitantes em cada Secretaria Regional era em torno de 250 a 300 mil. Porém a cidade vem crescendo, sobretudo, nos bairros das SER V e VI, que estão localizadas na região sul de Fortaleza e que não apresentam índices de desenvolvimento coerentes com o crescimento populacional.

Com os dados obtidos nos sites da Prefeitura de Fortaleza e da Secretaria de Saúde do Estado do Ceará (FORTALEZA, 2011; CEARÁ, 2011), estimou-se a razão entre população de cada SER e estabelecimentos de saúde, estimativa que fica em torno de $25 \mathrm{mil}$ habitantes por estabelecimento de saúde em cada SER. Com base nas mesmas fontes, em 2011, em média, eram 100 estabelecimentos de saúde para atender a uma população de 2.543.058 habitantes.

\section{População e amostra}

Participaram do estudo três categorias de profissionais do SUS, a saber: técnicos de enfermagem e/ou auxiliares de enfermagem; técnicos administrativos e/ou auxiliares administrativos; e técnicos em saúde bucal e/ou auxiliares em saúde bucal.

De cada uma das profissões de nível médio, foi composta uma pequena amostra com profissionais de várias UBS da cidade de Fortaleza, sendo as unidades escolhidas por um método aleatório. Foram sorteadas 12 instituições, duas de cada uma das seis SER, e uma parte dos técnicos existentes nessas instituições fez parte da amostra estudada. As UBS foram sorteadas com base em uma lista fornecida pela Prefeitura Municipal.

No total, foram entrevistados 25 profissionais, entre coordenadores, auxiliares de coordenação, auxiliares administrativos, auxiliares em saúde bucal e auxiliares e técnicos de enfermagem. Embora não tenha sido possível equalizar o número de entrevistas por UBS, procurou-se representar nesse grupo todas as unidades analisadas. Dentre as características requeridas, destacam-se: que em cada UBS sorteada fosse possível inquirir pelo menos um profissional de cada categoria estudada; que houvesse variação entre o gênero dos entrevistados; que o tempo de trabalho na unidade e no sistema de saúde fosse variado, procurando-se 
entrevistar técnicos que tivessem entrado recentemente na unidade ou sistema de saúde e técnicos que já trabalhassem no sistema há um certo tempo. Assim, em cada unidade, foram entrevistados o coordenador ou o auxiliar de coordenação e os profissionais técnicos disponíveis e que, voluntariamente, dispuseram-se a participar da pesquisa. Procurou-se seguir os critérios de variação de gênero e de tempo de trabalho, que variou de 2 meses a 30 anos.

\section{Materiais e procedimentos}

Inicialmente, apresentou-se estudo para a coordenação da unidade, para o qual ela - ou seu representante designado - foi convidada a participar. Em seguida, solicitou-se permissão para entrevistar os técnicos que aceitassem fazer parte da pesquisa.

As entrevistas versavam sobre as condições de trabalho da unidade, incluindo equipamentos e materiais utilizados no trabalho, sobre a quantidade, a formação e o treinamento de técnicos de nível médio, sobre a organização do trabalho e sobre os problemas de funcionamento.

As entrevistas foram efetivadas no próprio local de trabalho dos entrevistados, e, durante as visitas, foram também feitas observações das condições físicas da UBS com a utilização de uma lista de verificação, adaptada de Di Martino e Corlett (1998, p. 68-71). Essa lista, que continha itens versando sobre espaço físico, mobiliário, equipamentos, iluminação, ruído e ventilação, entre outros, não previa nenhum tipo de avaliação, tendo sido utilizada como um guia para as observações. Sua utilização visou, principalmente, dar apoio às entrevistas, mas parte da análise de conteúdo incluiu as observações feitas durante as visitas.

De acordo com as considerações sobre a ética em pesquisa, todos os entrevistados foram convidados a participar e receberam esclarecimentos sobre os objetivos da investigação. Depois disso, solicitava-se permissão para gravar as entrevistas, e o entrevistado assinava um Termo de Consentimento Livre e Esclarecido. O projeto de pesquisa foi analisado e aprovado pelo Comitê de Ética da Escola de Saúde Pública do Estado do Ceará.

As entrevistas foram transcritas e a análise do material obtido ocorreu em duas etapas. Inicialmente, as transcrições das entrevistas foram revisadas e preparadas para uma análise das Unidades de Contexto (UCE) contidas no vocabulário utilizado nos discursos das 25 entrevistas realizadas. Esse material foi então submetido a uma análise fatorial por correspondência, utilizando-se para isso o programa ALCESTE v2010. A partir das UCE, foi realizada uma análise de conteúdo temática (BARDIN, 1979), tendo como eixos as referidas UCE.

\section{Resultados}

O resultado da análise fatorial por correspondência mostrou a existência de quatro classes principais de UCE.

A Classe 1 (C1), 17\% das UCE, refere-se a palavras e termos mencionados por profissionais das várias SER, com significados relacionados à descrição do trabalho que realizam, aos equipamentos que utilizam e à formação e treinamento que os técnicos possuem.

A Classe 2 (C2), 8\% das UCE, mais mencionada por profissionais técnicos administrativos e coordenadores das SER I e IV, refere-se aos programas e à forma de atendimento da UBS.

A Classe 3 (C3), 54\% das UCE, é a que contém a maior frequência das UCE, correspondendo, portanto, ao vocabulário mais utilizado pelos entrevistados, particularmente pelos técnicos de enfermagem entrevistados. As palavras e as expressões utilizadas nessa classe referem-se a problemas relacionados às condições de trabalho, os equipamentos e ao atendimento nas UBS, bem como aos problemas de saúde decorrentes do trabalho.

A Classe 4 (C4), 21\% das UCE, a segunda mais frequente em termos da variação do vocabulário utilizado, refere-se também a questões das condições de trabalho, mas de forma positiva. Assim, essa classe se opõe à C3.

Em suma, as classes podem ser resumidas em:

Classe 1: Quantidade de técnicos e sua formação. Descrição do trabalho realizado e de equipamentos e de sistemas em uso na unidade.

Classe 2: A quantidade de atendimentos e as rodas de conversa.

Classe 3: Os problemas percebidos no trabalho.

Classe 4: Aspectos positivos do trabalho.

\section{Classe 1: os técnicos e seu trabalho}

\section{Contratação e formação}

Segundo os entrevistados, em média, as unidades possuem de 5 a 20 profissionais entre técnicos e auxiliares de enfermagem, em saúde bucal e administrativos. Em relação à contratação desses técnicos, a maioria é terceirizada, um indicativo da precarização dos vínculos. A seleção é realizada pela SER sem nenhuma intervenção da unidade. Isso tem como consequência a interferência da gestão política da SER sobre a unidade, o que, certamente, pode prejudicar a autonomia do coordenador da unidade no que diz respeito à alocação e à contratação dos profissionais. 
Taveira (2010), em uma revisão sobre os tipos de contrato de trabalho utilizados no SUS no Brasil, verificou que a diversidade de tipos de contratação se relaciona com a forma como o sistema foi sendo regionalizado e, sem emitir juízos de valor, acredita que possíveis desvios poderão ser corrigidos no futuro.

Para alguns coordenadores entrevistados, esse aspecto não chega a ser um problema, mas, sem dúvida, influencia o compromisso e a forma de trabalhar dos técnicos, principalmente ao se levar em conta o fato de que nem sempre os profissionais são alocados segundo suas habilidades e suas preferências. A solicitação e a demora (quando não há ausência de retorno) por parte da SER, no caso da contratação de mais profissionais, são citadas como uma das dificuldades da gestão da unidade.

Outro problema apontado pelos entrevistados é a não diferenciação salarial entre técnicos e auxiliares. Segundo eles, tanto faz possuir o curso técnico ou o antigo curso de auxiliar (de enfermagem), pois “o salário é o mesmo". É um fator de desestímulo para os profissionais que queiram seguir formação complementar para sair da condição de auxiliar para técnico. Apesar disso, a maioria dos entrevistados avalia positivamente sua formação, afirmando que ela permite desenvolver o trabalho adequadamente. Essa mesma afirmação transparece no discurso dos coordenadores e dos assistentes de diretoria.

A diferença entre auxiliares e técnicos de enfermagem está relacionada, sobretudo, à condição etária. Em geral, os mais velhos ou que estão em atividade há mais tempo relatam ter cursado o nível de segundo grau e recebido o certificado de auxiliares de enfermagem. Já os técnicos de enfermagem são aqueles que realizaram cursos técnicos mais recentemente, por meio do Projeto de Profissionalização dos Trabalhadores da Área de Enfermagem (PROFAE) ou cursos particulares. Conforme os Referenciais Curriculares Nacionais da área da saúde, os cursos técnicos são: Biodiagnóstico, Enfermagem, Estética, Farmácia, Hemoterapia, Nutrição e Dietética, Radiologia e Diagnóstico por Imagem, Reabilitação, Saúde Bucal, Saúde Visual, Segurança do Trabalho e Vigilância Sanitária (PEREIRA; LIMA, 2008).

Sou técnica em enfermagem... Vou terminar em janeiro. Há uns 10 anos atrás, eu fiz o curso de auxiliar e, na época, era oferecido com nível de segundo grau. A gente recebia certificado como se tivesse feito curso de segundo grau. Porque antigamente só tinha científico e pedagógico, surgiu esse curso técnico, né? Ele é reconhecido no COREN e no governo. $O$ que a gente aprende realmente é voltada à área, e a gente consegue realmente pôr em prática. O que é que está acontecendo é que, como na época a gente tinha um tipo de auxiliar de enfermagem e agora o COREN vai extinguir essa função, então tá sendo exigido o título de técnico, por isso muitos de nós estamos fazendo complementação do curso para ver se tira. (Técnica de enfermagem)
Embora a avaliação da formação adquirida seja boa, há críticas ao custo elevado dessa formação e queixas de que as disciplinas voltadas para a "realidade prática" do dia a dia da sua profissão ficaram aquém das expectativas, quando foram confrontados com o cotidiano do seu trabalho.

Precisaria de mais, uma formação mais completa, mais voltada à atenção primária. (Coordenadora de SER)

Mas, na prática... Acho que a teoria ela é boa, mas tem muito a desejar, tá entendendo? Eu acho que são muitas coisas sem noção, sem utilidade, tá entendendo? $\mathrm{Eu}$ acho que os cursos deveriam ser mais em cima do que você vai trabalhar [...] (Auxiliar e técnica de enfermagem)

\section{Descrição do trabalho}

A maioria dos auxiliares e técnicos de enfermagem deu grande ênfase às suas atividades de acolhimento dos pacientes, considerando-as como fundamentais no cotidiano do funcionamento da unidade e relacionando as características desse serviço com a satisfação/insatisfação do usuário. É no acolhimento que parece acontecer uma tentativa, por parte desses profissionais, de sanar as deficiências da unidade de saúde como um todo, amenizando ou "driblando", durante o contato direto com o usuário, sua possível insatisfação com situações comuns no cotidiano da unidade, tais como a falta de medicamentos, o número limitado de fichas para atendimento médico etc.

Alguns técnicos realizam serviços específicos, como a administração de vacinas, a troca de curativos, a aplicação de aerossol, a verificação de sinais vitais e a administração e distribuição de medicamentos, além, é claro, dos serviços específicos prestados pelos auxiliares e pelos técnicos de consultório dentário. Os profissionais também costumam participar dos programas planejados pelo Ministério da Saúde (programa para diabéticos, hipertensos, tuberculose, entre outros) e de atividades externas às unidades (programas preventivos e educativos).

No caso da existência de equipamentos de informática, os auxiliares e os técnicos realizam o preenchimento de fichas eletrônicas dos pacientes e, às vezes, a marcação de consultas e de exames solicitados pelos médicos. Na falta desses equipamentos, eles preenchem prontuários e fichas manualmente.

\section{Classe 2: a quantidade de atendimentos e as rodas de conversa}

\section{Quantidade de atendimentos}

O atendimento nas UBS é regulado pela quantidade de profissionais (técnicos e de nível superior) da unidade. Assim, há uma grande variação na forma e no número 
de pessoas atendidas em um dia de trabalho. Além disso, o número de atendimentos varia de acordo com as campanhas planejadas pelo Ministério da Saúde e pela Secretaria da Saúde. Quando há campanhas, por exemplo, de vacinação, cada profissional técnico chega a atender mais de 100 pacientes por dia. Na média, porém, os profissionais técnicos atendem entre 16 e 100 pessoas por dia de trabalho. Assim, a carga de trabalho dos profissionais é bastante pesada e o esforço despendido no trabalho pode levar a problemas de saúde, principalmente de saúde mental, como mostra o estudo de Stacciarini e Tróccoli (2001).

Nesse sentido, os agravos à saúde desses profissionais repercutem na forma de atendimento ao que ficou esclarecido na observação do trabalho pelos pesquisadores. Em algumas UBS, foram presenciados inúmeros conflitos entre esses profissionais e pacientes. Esses tumultos têm sido responsáveis por agressões e por atitudes impensadas tanto por profissionais quanto por usuários.

As rodas de conversa

Alguns profissionais citaram reuniões internas, denominadas de "rodas de conversa", as quais deveriam ocorrer periodicamente a fim de proporcionar um trabalho melhor para a comunidade, com a troca de informações sobre os atendimentos realizados e os problemas encontrados na realização do trabalho. Teoricamente, a roda de conversa consiste em uma dinâmica de debates acerca de uma temática, mediante a criação de espaços para o diálogo, nos quais os sujeitos podem se expressar e, sobretudo, escutar os outros e a si mesmos. Tem como principal objetivo motivar o estabelecimento da autonomia por meio da problematização, da socialização de saberes e da reflexão voltada para a ação. Essas reuniões são, em geral, vistas pelos entrevistados como necessárias e produtivas, embora não aconteçam com a periodicidade com que deveriam. Um dos coordenadores destacou a necessidade das rodas para sempre alertar os profissionais para a qualidade no acolhimento, ou seja, no tratamento dispensado ao usuário logo que ele chega à unidade, seja dando a informação correta de que ele necessita para resolver o problema que o levou até a unidade, seja justificando, de forma clara, quando ocorre a impossibilidade de se prestar o serviço necessário para solucionar seu caso.

Porque nós temos as nossas rodas, a gente conversa com eles. Alguns informes. A gente procura sempre orientar para dar um bom atendimento, que é o nosso objetivo. (Coordenador de SER)
Porque, assim, a gente tem conselho, reunião de conselho, tem as rodas atuando. Faz as terapêuticas, faz aquelas conversas [...] minirrodas que a gente chama... até, assim, porque não necessariamente aquela roda geral, sempre faz dos setores, para exatamente não ter que parar [...] Em roda [...] a gente toda vida tem que fazer uns espaços sociais, isso é muito bom também, mas, infelizmente, muitas vezes a gente não consegue. (Coordenadora de SER)

Griffiths, Maben e Murrells (2011) atestam a importância de oferecer treinamentos e capacitações para a melhoria do atendimento aos pacientes, seguindo a mesma linha de Ceccim, Armani e Rocha (2002). A capacitação dos profissionais técnicos de nível médio deveria acontecer como um continuum, e não apenas até a conclusão do curso e da emissão de diploma, pois o lidar com a saúde do indivíduo requer um aperfeiçoamento contínuo e ininterrupto, visto que a formação fragmentada e teórica impossibilita uma atualização e favorece uma atuação apenas com base em procedimentos técnicos (SARACENO; ASIOLI; TOGNONI, 1997).

\section{Classe 3: os problemas percebidos no trabalho}

\section{A demanda}

O excesso de demanda, como um fator que compromete a qualidade do atendimento a ser prestado, foi um dos principais problemas relatados em relação ao trabalho, quando comparado com os recursos humanos e materiais disponíveis para se prestar os serviços. Embora a relação população atendida/unidade de saúde seja em média de 25.451 habitantes por unidade, essa proporção leva em consideração todos os aparatos dos sistemas terciários e secundários ${ }^{5}$. Todos os usuários, no entanto, devem ser, primeiramente, atendidos pelo sistema primário, os postos de saúde. Assim, há postos que devem atender a uma população de 50 a 60 mil pessoas (a população que reside na região da unidade, denominada de população adscrita).

A demanda é muito grande, é de 45 a 50 mil usuários.
É muita gente. É mais ou menos essa média que a
gente tem cadastrada. (Assistente de coordenação)
É muita gente mesmo, porque, às vezes, chega gente
fora do horário e querem ser atendidos também fora de
horário também, entende? Às vezes nem tem médico
nem nada. O pessoal procura muito mesmo. Eu ainda
acho pouco porque é muita gente para esse posto. E
a fila aumentando. Para as pessoas não ficarem
estressadas na fila. A gente se preocupa com isso. Tem
pessoas que tá na fila e não têm paciência. E aí a
gente fica preocupada. Botar pra frente ninguém pode
porque os outros da frente vai reclamar. (Técnica de
enfermagem)

5 O SUS é um sistema dividido em três níveis de atenção. A atenção primária se refere ao atendimento prestado nas UBS (porta de entrada do sistema). O sistema secundário refere-se ao atendimento em unidades especializadas, e a atenção terciária, aos atendimentos de alta complexidade, geralmente prestados em hospitais. 
Você viu, são 27 mil habitantes, então, assim, por exemplo, a garota muitas vezes fica sobrecarregada. (Coordenadora de SER)

É tanto que a nossa demanda é muito grande. São mais de 35 mil pessoas que o posto abrange. (Coordenador de SER)

Esse problema tem sido identificado como fonte de estresse tanto de profissionais, incluindo os gestores, quanto da população que não encontra condições de atendimento adequadas.

\section{Problemas na estrutura física e equipamentos}

Um dos aspectos observados e relatados no discurso dos entrevistados se relaciona às condições físicas e à estrutura do local de trabalho (sua precariedade), bem como à falta de equipamentos e de materiais. Esse é um dos fatores que chega a ser mencionado com certa angústia, sobretudo quando a resolução de tal dificuldade está fora do alcance do profissional de nível médio e está relacionada à infraestrutura da unidade como um todo, com a carência de profissionais de nível superior para o atendimento ou ainda com a carência de material disponível para realizar determinados procedimentos, tais como material para fazer curativos.

A gente tem muita necessidade de material, de condições de trabalho, certo? Porque, assim, eu trabalho na sala do peso, do aerossol, certo? Se você vê a sala do aerossol! Acho que não tem nem condições de se fazer um aerossol lá. Primeiro, com a higienização da sala; segundo, com o ambiente. Você tá entendendo? Não é adequado. É bem precária. É uma sala que era pra ser bem equipada. Sempre ser limpa. Sempre higienizada. (Auxiliar e técnica de enfermagem)

Mas, assim, o que mais incomoda a gente é a forma de trabalho... Que o material da gente é um pouquinho. A gente se vira com o que tem, né? (Técnica de enfermagem)

Com relação à limpeza, por exemplo, está necessitando. Olha essa maca! Mil novecentos e eu me esqueci. Está precisando mudar. Para mim, um ambiente, um local onde se trabalha com saúde tem que ser impecável, tem que ser limpo, limpo. Eu vou limpar a sala do curativo, eu não vou só tirar o lixo. Eu tenho que limpar, tenho que varrer, tenho que passar o pano, certo? Isso falta. Pra mim esse é um ponto negativo. (Técnica de enfermagem)

Então, é como eu te digo. O nosso posto ele está quase todas as salas interditadas. Então, por enquanto eles não estão atendendo. A sala de odonto está toda interditada. A sala de prevenção está toda interditada. Então, as meninas normalmente só usam o computador, o sistema, e o resto é tudo feito manual. Está tudo interditado, enferrujado, já foi condenado, por isso que a gente vai sair pra reforma. (Coordenador de SER)
Aí a gente parou porque a enfermeira interditou a prevenção e eu interditei aqui porque olha o teto? Tem coisas que é porque é antigo, tem a defasagem do tempo, dos materiais. A cadeira tem 30 anos. O motor parou, o que é que a gente pode fazer? (Auxiliar em saúde bucal)

Muitas foram as queixas registradas pela equipe sobre o sucateamento das unidades de saúde. Nesse cenário, a população que busca atendimento nem sempre fica satisfeita. Quando não faltam recursos humanos, faltam materiais de consumo e infraestrutura.

Em várias das unidades visitadas, pode-se comprovar, pelas observações, a falta de material e de condições adequadas de funcionamento, por exemplo, equipamentos sem manutenção, cadeiras e mesas quebradas, locais pouco iluminados, entre outros. Em alguns casos, os entrevistados afirmaram que pequenos consertos e até o empréstimo de cadeiras, mesas e suprimentos são realizados e financiados pelos próprios trabalhadores.

\section{Equipamentos e sistemas utilizados}

Os entrevistados, quando perguntados, queixaram-se de uma série de equipamentos existentes na unidade de uso dos técnicos e dos auxiliares. Em geral, são equipamentos de informática (computadores e impressoras) e equipamentos médicos e odontológicos, como o sonar, os medidores de pressão, os estetoscópios, as autoclavesetc. A qualidade dos sistemas implantados e a quantidade de máquinas para a operacionalização dos procedimentos são os principais motivos de queixas por parte dos profissionais que os utilizam. Eles chegam a informar que essa deficiência tem por consequência a lentidão no atendimento como um todo. Em algumas unidades, os computadores e os sistemas parecem funcionar adequadamente; em outras, esses equipamentos são velhos ou permanecem sem manutenção. Como se pode perceber pelos trechos de discurso transcritos a seguir, todas as unidades analisadas fazem uso de sistemas informatizados, sendo que os sistemas de marcação de consultas, agendamentos e prontuários são os mais citados.

Nós temos o prontuário eletrônico, no qual eu pego todos os dados do paciente, né? Porque antes é feito um cadastro, aí eu uso esse meio da internet para registrar as vacinas nas quais a pessoa procurou para tomar aqui. Fica tudo registrado. (Técnica de enfermagem)

Tem um sistema de cadastro de vacina que faz o acompanhamento do histórico do paciente. Esse programa é integrado com a regional geral que acompanha o andamento das vacinas. (Auxiliar de enfermagem)

Quando perguntados sobre os equipamentos de informática, embora tenham afirmado a sua existência e explicado como fazem parte de suas atividades, a maioria se queixa da falta de manutenção e de equipamentos mais adequados. 
Sobre essa parte aí 'das informáticas', né? Porque aqui nós, que trabalhamos no acolhimento, não temos computador. Na prevenção também tinha, mas não tem mais computador lá. Está com problema... no curativo a mesma coisa. No curativo nunca teve. É para ter, mas nunca teve computador. (Técnica de enfermagem)

Se funcionasse! [o equipamento] [ri]. Se funcionasse, com certeza atenderia [às necessidades], né? Mas [...] Está suspensa [...] o consultório está quebrado. Está com cinco meses que eu estou aqui, até agora não consertaram. E agora os dentistas estão em greve, né? (Auxiliar em saúde bucal)

Alguns dos entrevistados localizam a fonte do problema em questões administrativas, falta de apoio e ausência de organização e de comunicação com as SER, ficando as unidades sujeitas aos desmandos políticos. Notou-se também que há um esforço por parte de muitos profissionais em solucionar com recursos da própria unidade alguns problemas que são da competência das SER.

Muda muito o cenário político de Regional para Regional, de quantos vereadores têm. Tu estás me entendendo? De liderança comunitária. Então, tem postos que são magníficos e tem postos que são como esse, entendeu? (Auxiliar em saúde bucal)

\section{A segurança}

Nesta categoria foram organizados os trechos que dizem respeito aos riscos relacionados às agressões físicas e aos delitos praticados tanto pelos usuários quanto por pessoas que assaltam os postos de saúde, arrombam carros dos trabalhadores e agridem profissionais e usuários. Um dos fatores que contribuem para isso é a própria localização desses postos, que, em geral, estão em áreas de risco e não possuem um sistema de segurança. Alguns profissionais informaram que não é raro o desvio de função de algum profissional terceirizado da área da limpeza para cumprir a função de "segurança" da unidade, ainda que precariamente e sem nenhuma preparação para a tarefa.

Às vezes, a gente teme porque a gente trabalha em área de risco e tem muita [...] mulher [...] mas tem mesmo. É perigoso aqui. É muito perigoso aqui. A gente não se sente segura não, porque aqui não tem nenhuma segurança. (Técnica de enfermagem)

A gente tinha um problema com viciados, usuário de droga. Eles vinham atrás de medicamentos para vender, para trocar por alguma coisa, então a gente se sentia constrangido. Mas a gente já sabia que eles vinham frequentemente. Às vezes, a gente era ameaçado, mas também cada um agia da maneira que deveria agir. Mas graças a Deus, apesar de não ter vigilante, de não ter segurança, tem os meninos. Os meninos que ficam na portaria, mas nem toda vez eles estão presentes na hora que acontece algum fato. São eles que ajudam. Mas eles não têm formação. Eles são dos serviços gerais, são terceirizados, função desviada. (Auxiliar e técnica de enfermagem)
Falta de profissionais, baixos salários e falta de reconhecimento

A falta ou a insuficiência de médicos tem sido uma realidade identificada em todas as unidades de saúde observadas. Esse problema recai no acúmulo de trabalho para os profissionais de nível técnico, além dos conflitos pelas reclamações da população, já que esses profissionais são responsáveis pelo acolhimento e pela triagem. É nesses momentos que a falta de um médico pode incorrer em manifestações agressivas de descontentamento dos usuários.

Às vezes, não tem médico, porque na unidade tem pouco médico. (Auxiliar de enfermagem)

A carga horária do médico não é boa e o pessoal reclama muito da carga horária do médico Como eu te falei, tem vez que o médico não vem. Aí fica mais complicado pra gente. (Auxiliar administrativo)

Assim, a gente tenta atender, só que tem ainda muito... como é que eu posso dizer [...] dificuldade, né? Em termos de médico, essas coisas. Porque a demanda é muito grande para pouco profissional médico. (Auxiliar de enfermagem)

Alguns se referem à questão dos baixos salários pagos aos profissionais da saúde. Muitos acentuam não ser uma área na qual há retorno financeiro adequado e alegam permanecer nela por identificação com o ofício.

Assim, há pessoas que dizem que é melhor ser um zelador do que ser um auxiliar. É, tem gente que diz assim. Porque o auxiliar não ganha como ele deveria ganhar e o zelador ganha mais do que a gente. Está entendendo? Isso acaba desestimulando. (Auxiliar e técnica de enfermagem)

A gente não tem um salário muito bem adequado, é defasado. A empresa [terceirizada], ela não atende às necessidades da gente. Ela não paga em dia. Para dar férias é muito demorado. É isso. A gente merecia ter um salário melhor. A gente ganha R\$ 570 por mês e tem vezes que algumas das colegas recebem menos. A gente pega o contracheque e procura a diferença e o porquê da diferença e não entende. Eu sei que a Prefeitura deve repassar um valor maior e eles, não sei por que, não pagam adequadamente. (Técnica de enfermagem)

Os entrevistados queixaram-se da falta de reconhecimento de seus superiores e dos usuários das unidades. Reclamam que, a despeito dos esforços, além de não serem reconhecidos, ainda costumam ser culpados por erros de profissionais de nível superior.

Mulher, assim, a gente se dedica ao máximo, certo? Nós que somos auxiliares nos dedicamos ao máximo e não somos reconhecidas. (Técnica de enfermagem)

O não reconhecimento pode levar o trabalhador à insatisfação e a sentimentos negativos que irão repercutir no atendimento aos usuários e, por conseguinte, na ampliação do sentimento de insatisfação para além dos muros das unidades de saúde. 


\section{Treinamento e capacitação}

Além da falta de profissionais, há também uma insatisfação quanto à capacitação e ao treinamento, embora alguns relatem ter participado de cursos de capacitação e de treinamento ou citem cursos em andamento ofertados pela Prefeitura. Quando o treinamento existe, ele parece ser bastante precário, realizado durante o próprio serviço ou por iniciativa própria.

[Foi treinada para usar esses aparelhos?] Assim, o aparelho de pressão, sim. Agora os computadores, não. [Aprendeu como?] Na marra. Com a cara e coragem. (Auxiliar de enfermagem)

Não houve treinamento. Só mesmo de boca mesmo. É porque eu já sei mexer, mas, se chegar uma senhora aqui que nunca tiver pegue, a gente ó! É isso, assim e pronto, não tem treinamento não. (Auxiliar de enfermagem)

Mas aquele treinamento deixa a desejar. Porque eu não acredito que um treinamento seja num dia, em meia hora, em meio expediente. Sempre há uma dúvida, né? (Auxiliar e técnica de enfermagem)

Aulas de informática, inclusive eu fiz até um cursinho básico por iniciativa própria. Porque eu já tinha e só fiz reforçar. (Técnica de enfermagem)

Existem, porém, alguns cursos oferecidos pela Prefeitura, segundo depoimentos dos coordenadores. Entretanto, reconhecem que nem todos os profissionais de nível médio conseguem ser liberados para esses treinamentos, geralmente de curtíssima duração e em horários que deveriam ser utilizados para o descanso dos trabalhadores.

Inclusive tem duas auxiliares de enfermagem e duas agentes em saúde bucal que elas saíram hoje de manhã porque elas estão fazendo curso de esterilização. Então, sempre quando tem alguma coisa nova, a Regional, a Prefeitura, eles disponibilizam cursos de aperfeiçoamento. (Coordenadora de SER)

Assim, alguns entrevistados asseveram a importância de oferecer treinamentos e capacitações para a melhoria do atendimento aos pacientes. Griffiths, Maben e Murrells (2011), estudando a relação entre qualidade do cuidado, formação técnica e fatores organizacionais, chegam à mesma conclusão, expressando os benefícios e a importância da educação, do treinamento e do desenvolvimento pessoal dos profissionais de enfermagem para a qualidade dos atendimentos.

Ceccim, Armani e Rocha (2002, p. 375) estudaram os textos legais de ordenamento do SUS e os relatórios da Conferência Nacional de Saúde, que apontam as responsabilidades da gestão do SUS para com o desenvolvimento e a formação de recursos humanos em saúde. Na sua análise, atestam que o SUS é responsável pela formação de pessoal de saúde de modo geral e pela produção específica de conhecimento e de tecnologia no âmbito do próprio sistema. Analisando outro trecho da legislação, os mesmos autores ressaltam que a ação educacional é atribuição dos órgãos de gestão do SUS, ao qual são cabíveis a formulação e a execução de programas que envolvam a certificação/habilitação profissional, a educação continuada de recursos humanos para a saúde e a produção de conhecimentos, de informações e de atualização técnico-profissional.

\section{Relação saúde e trabalho}

Nos discursos dos entrevistados, o trabalho aparece como um indutor de problemas de saúde, às vezes específicos, às vezes relacionados ao cansaço e ao estresse decorrente das tarefas diárias e da alta demanda de pacientes nas unidades.

Eu já tive um acidente de trabalho por descuido no manuseio dos materiais. Sim, o trabalho afeta a sua saúde, pois é um ambiente insalubre. Tenho tendinite e já tive LER/DORT. (Auxiliar em saúde bucal)

O trabalho afeta muito, por exemplo, a gente lida com solução enzimática. Você lida com álcool, hipoclorito. Tudo isso é uma coisa que embora eu use o equipamento, mas a pele da gente ele transmite. Aquele cheiro ali entra na pele da gente. Por mais que você se previna, mas, de qualquer forma você, tá em contato e aquilo, às vezes, resseca o nariz. [...] Você é que tem que se virar. (Técnica de enfermagem)

A gente acaba estando muito exposta às bactérias, não é? Eu procuro sempre ter um cuidado, estar de luva, usar a máscara. (Técnica de enfermagem)

O cansaço e o estresse da atividade parecem ter relação tanto com a alta demanda de trabalho quanto com as condições precárias em que realizam suas atividades e até com a impossibilidade de realizá-las em virtude da interdição de salas de trabalho. Alguns chegam mesmo a dizer que as condições precárias de que dispõem para realizar seu trabalho são um fator mais angustiante do que sua baixa remuneração. Há certa recorrência também em culpabilizar o usuário, ainda que de forma discreta, pela carga de estresse no trabalho. Outros ainda relatam que a baixa escolaridade da população é um dos fatores que compromete o bom relacionamento com o usuário.

Por incrível que pareça [o meu trabalho] afetou [minha saúde]. Quando eu cheguei aqui, eu não tinha problema de pressão. Como aqui abrange uma área maior e o pessoal perturba demais, entre aspas, né? Hoje em dia, até pressão alta eu já tenho. (Auxiliar administrativo)

Eu acho assim: é muito desgaste pra mim, porque eu fico aqui no peso, fico lá no aerossol, fico lá na medicação e tem hora que você se estressa e passa o estresse para o paciente. Você fica superignorante 
com os pacientes. Aí eu acho que é muito desgaste pra mim. É muito puxado. Eu fico muito cansada, cansaço mental, quando dá a lotação, e fico cansada demais que, quando eu chego em casa, eu capoto. É o cansaço. (Auxiliar de enfermagem)

Apesar de negar problemas decorrentes do trabalho, estas duas entrevistadas acentuaram o estresse em função do trabalho.

[Acha que o seu trabalho afeta a sua saúde de alguma forma?] De maneira nenhuma. Umas das vezes eu me estresso, mas é muito difícil. (Auxiliar de enfermagem)

Nunca percebi isso. Assim, no começo, a gente para se adaptar é muito difícil, você não consegue esquecer as coisas do trabalho, acaba levando pra casa e de casa acaba trazendo pro trabalho. Isso é todo um estudo. Você tem que se preparar, você tem que ter consciência de que o que é casa é de casa e o que é do trabalho é do trabalho. Quando eu saio daqui, eu esqueço o posto... e vou cuidar da minha vida doméstica. Eu aprendi assim. (Auxiliar e técnica de enfermagem)

\section{Classe 4: aspectos positivos do trabalho}

Identidade e significação do trabalho

O trabalho nem sempre é visto como fator de adoecimento. Alguns atribuem a si a vocação de servir ao próximo, como se isso amenizasse as condições de precarização a que se submetem. Encaram seu trabalho como caridade, como uma doação à comunidade carente.

Eu me identifiquei muito com saúde pública e amo a minha profissão. Faço por amor. (Auxiliar de enfermagem)

Positivo só o prazer da profissão mesmo. Porque a gente gosta, faz. Tem que gostar porque, se você não gostar, não adianta. É uma coisa que você tem que fazer por amor. Porque dinheiro não compensa. Compensa não porque é uma área de risco. Você tem muito contato com coisas que só Deus acalma. Então a dedicação é mesmo para quem gosta. (Técnica de enfermagem)

Eu sempre digo que eu não vou para o meu trabalho, eu vou para minha missão. Eu acordo de manhã e peço a Deus que me abençoe, que me ilumine, que abençoe meus pacientes, porque é uma missão. Trabalhar com vidas, pra mim é uma missão. (Técnica de enfermagem)

Eu gosto de trabalhar nessa área, sabe? Porque, tentando ajudar, tem muita gente carente que não sabe nem como se trata da sua própria boca, né? Aí eu gosto muito. (Auxiliar em saúde bucal)

Aspectos positivos da unidade e dos profissionais em geral também foram citados.

Temos médicos muito bons que trabalham muito bem... as enfermeiras. Temos uma coordenadora, agora, que é muito boa. (Técnica de enfermagem)
Relação com a comunidade

Alguns coordenadores e técnicos citaram a boa relação que os técnicos conseguem manter com a comunidade atendida, incluindo relações com a vizinhança do posto e com a comunidade local como um todo. Observou-se que muitos profissionais conhecem e tratam os usuários pelos nomes, constituindo isso motivo de indisfarçada satisfação por parte do usuário.

A gente consegue manter um vínculo muito grande com as famílias da área. Um vínculo até, às vezes, afetivo, de carinho. A gente conhece a família todinha, né? A gente conhece a árvore genealógica daquela família todinha. Não são as famílias todas, pois há um absurdo de famílias que a gente tem. (Coordenadora de SER)

\section{Discussão}

A análise fatorial por correspondência dos discursos dos técnicos das UBS de Fortaleza indicou quatro classes principais de UCE. Já a análise de conteúdo identificou pelo menos 12 categorias, a partir do discurso dos profissionais, que interferem nas condições do trabalho do pessoal técnico de nível médio. No entanto, as observações feitas nos locais de trabalho complementaram as análises realizadas, pontuando, de forma mais clara, os aspectos das condições de trabalho mencionados pelos profissionais. Dessa forma, o estudo foca, como principal entrada de dados, o próprio trabalhador e seu discurso como preconizado pelos métodos ergonômicos centrados no trabalhador, mas sem prescindir das observações dos locais de trabalho, método auxiliar ao entendimento do discurso dos trabalhadores.

Entretanto, em termos de procedimentos de análise, a pesquisa traz a análise fatorial por correspondência preliminar como um catalisador do que é central nos discursos, seguida da análise de conteúdo, para uma melhor discriminação dos principais aspectos contidos nesses mesmos discursos.

Tanto os procedimentos de coleta dos dados (entrevistas e observações) quanto os procedimentos de análise não seguiram rigorosamente os procedimentos técnicos da Análise Ergonômica do Trabalho (AET), mas foram suficientes para permitir uma compreensão do trabalho realizado pelos técnicos e auxiliares do SUS nas UBS, suas principais preocupações e os aspectos do trabalho que mostram a precarização do sistema, bem como um diagnóstico das condições e da organização do trabalho, resumidos a seguir, que podem levar a sugestões de melhorias.

Verificou-se que a quantidade de técnicos e auxiliares das UBS estudadas variou de 5 a 20 profissionais por unidade. Levando-se em conta 20 técnicos ou 
auxiliares por unidade, pode-se estimar que cada SER possui aproximadamente 100 técnicos de nível médio, 1 para cada 2.543 pessoas, o que não parece ser uma razão satisfatória. Para os Agentes Comunitários de Saúde (ACS), que devem realizar visitas às residências das famílias adscritas à unidade básica, calcula-se uma média de 500 a 700 habitantes para cada ACS (PEREIRA; BARCELLOS, 2006). Embora o pessoal técnico das UBS atenda apenas aos usuários que se dirigem à unidade, a razão habitantes / profissional chega a ser três vezes mais elevada que o de um ACS e, dependendo da carência da população atendida, pode significar uma sobrecarga de trabalho, tendo em vista que o contato com o público na triagem e no acolhimento é constante.

O tipo de contrato mantido com o SUS, no caso dos profissionais de nível médio de Fortaleza, compreende, basicamente, terceirizados. Apesar disso, a maneira como esses técnicos são selecionados ou indicados é o que mais chama atenção. Segundo os relatos, a seleção é realizada pela Secretaria Regional da Prefeitura, sem nenhuma intervenção da unidade. Essa centralização interfere na autonomia dos gestores da unidade e, consequentemente, pode repercutir negativamente nas relações de trabalho.

No que se refere à formação dos técnicos e auxiliares, o discurso dos técnicos e de seus coordenadores é de que os cursos oferecidos no mercado são bons e que o aprendizado proporcionado por eles é adequado às necessidades do trabalho. Alguns profissionais se queixam, no entanto, de que as disciplinas voltadas para a "realidade prática" do seu trabalho ficam aquém das expectativas.

A questão do ensino-aprendizagem é um dos pontos discutidos nos programas de ensino para a área da saúde. Por exemplo, Almeida e Ferraz (2008, p. 34-35), revisando o assunto, concluem que para ser ter uma formação e uma capacitação que integre a educação e os serviços de saúde, a exemplo do PROFAE e, mais recentemente, do Programa Nacional de Reorientação da Formação Profissional em Saúde (PRÓ-SAÚDE), é necessário aplicar uma educação planejada para enfrentar e para corrigir as distorções do sistema. Além disso, a formação não deve ser um processo estático, mas o SUS deve oferecer aos profissionais de saúde uma educação e uma capacitação continuada (PEREIRA; LIMA, 2008). Acrescente-se a essa observação a necessidade de envolver todos nesses processos, e não somente os que possuem vínculos permanentes com as unidades.

Segundo os relatos dos entrevistados, no entanto, essa formação continuada ainda está distante das necessidades do setor. A maior parte dos técnicos se queixa da falta de oportunidades de capacitação e de treinamento, referindo-se à capacitação nas atividades relacionadas ao atendimento em saúde e, principalmente, na chamada humanização como a forma de tratamento com que os pacientes devem ser atendidos - o chamado acolhimento.

As reuniões periódicas, chamadas de rodas de conversa, podem suprir parte da capacitação e do treinamento ao procurar discutir os problemas encontrados no trabalho e verificar as principais deficiências dos técnicos na realização de suas atividades. Poucos descreveram, contudo, a realização dessas rodas e alguns enfatizaram que elas não ocorrem com a periodicidade com que deveriam por absoluta falta de tempo (leia-se falta de pessoal suficiente para dar conta da alta demanda de trabalho).

A superlotação causada pelo grande contingente de usuários e o consequente excesso de demanda interferem decisivamente nas condições de trabalho. Muitos relatos denunciam que as condições de infraestrutura e a falta de material e de medicamentos comprometem a qualidade do atendimento a ser prestado. Alguns dos entrevistados localizam a fonte do problema em questões administrativas, na falta de apoio e de organização e de comunicação com as SER, ficando as unidades sujeitas aos desmandos políticos. Foi observado nas entrevistas e nas visitas que há um esforço por parte de muitos profissionais em solucionar alguns desses problemas com recursos próprios.

Esse cenário de carências resulta em insatisfação de profissionais e de usuários das unidades de saúde. Assim, a carga de trabalho dos profissionais é bastante pesada e o esforço despendido no trabalho pode levar a problemas de saúde, principalmente de saúde mental, como mostra o estudo de Stacciarini e Tróccoli (2001).

Outro ponto bastante citado diz respeito à falta de profissionais médicos e de pessoal para cobrir férias e outras eventualidades. Alguns se referem aos baixos salários pagos aos profissionais da saúde. Muitos dizem não ser uma área com retorno financeiro adequado e alegam permanecer nela por identificação com o seu mister. É interessante notar que o Brasil não está sozinho no que se refere ao pagamento de baixos salários aos profissionais cuidadores com escolaridade mais baixa. Muntaner et al. (2006) estudaram a questão dos baixos salários e da pobreza dos cuidadores da área da saúde nos Estado Unidos. Na introdução do trabalho, garantem que, nos serviços de saúde americanos, 60\% dos trabalhadores são mal pagos, incluindo os auxiliares de enfermagem, atendentes pessoais e cuidadores a domicílio, assinalando que o salário que ganham os mantém na fronteira ou abaixo da linha de pobreza.

As consequências do trabalho precarizado, no qual as condições laborais são pouco satisfatórias e a carga de trabalho é elevada, além da angústia de não poder 
realizar um trabalho mais eficiente e de acordo com as expectativas individuais, levam os profissionais de nível médio a relatar problemas de saúde relacionados ao trabalho. Alguns chegam mesmo a afirmar que as condições precárias de que dispõem para realizar seu trabalho são um fator mais angustiante do que sua baixa remuneração.

Apesar da precariedade das condições de trabalho e dos inúmeros problemas relatados, alguns profissionais apontam aspectos positivos do trabalho que realizam. Boa parte dos entrevistados demonstra identificação com o ofício que escolheram, valorizando a importância social do seu trabalho e a sua vocação, e avalia positivamente suas relações socioprofissionais.

\section{Considerações finais}

Os resultados mostraram que as condições de trabalho e, portanto, do atendimento aos usuários são precárias tanto no que diz respeito às condições materiais quanto à organização das tarefas e das atividades. Os custos desse trabalho, realizado em condições precárias, refletem-se sobre a saúde dos profissionais que se mostram exaustos física e emocionalmente. Nessas circunstâncias, acabam por transparecer suas mazelas aos usuários, os quais, por sua vez, possuem um perfil de reféns da desigualdade e da pobreza, gerando insatisfação generalizada no interior das unidades e no sistema de saúde.
As observações das condições de trabalho das UBS, bem como as entrevistas com os técnicos e com os auxiliares, permitiram a verificação da enorme distância entre o trabalho preconizado para o atendimento em saúde do SUS e as reais condições de trabalho a que ficam sujeitos os trabalhadores de nível médio das diversas unidades analisadas. Como é possível oferecer um atendimento de qualidade em condições e em organização de trabalho tão precárias? O fato de a organização do trabalho e as condições físicas das unidades ficarem aquém do esperado para um atendimento de qualidade leva o trabalhador a uma adaptação forçada, induzindo-o, algumas vezes, a compensar as falhas por sua própria conta e risco e prejudicar sua saúde, o que, por sua vez, reverte para o sistema, precarizando-o ainda mais. Trata-se de um círculo vicioso difícil de suplantar.

Por fim, algumas sugestões podem ser retiradas de nossos resultados: (1) as diretrizes norteadoras do projeto de intervenção nos novos dispositivos de saúde devem levar em consideração a mudança de vínculo dos profissionais, em grande parte terceirizada; (2) deve-se aumentar o número de profissionais de saúde de tal forma a corresponder à real demanda de atendimento; (3) melhorar as condições de trabalho, ou seja, as condições físicas de estrutura e técnicas de equipamentos e suprimento de materiais, além de vínculos equitativos de salários e de benefícios, incluindo aí a formação e o treinamento, para que essa categoria possa desempenhar com mais eficácia e dignidade o seu trabalho.

\section{Contribuições de autoria}

Maciel, R. H. M. O. e Santos, J. B. F.: participaram da concepção metodológica do projeto, da coleta e análise dos dados, da redação e revisão final do artigo. Rodrigues, R. L.: participou da análise dos dados, da redação e revisão final do artigo.

\section{Referências}

ALMEIDA, L. P. V. G. D.; FERRAZ, C. A. Políticas de formação de recursos humanos em saúde e enfermagem. Revista Brasileira de Enfermagem, Brasília, v. 61, n. 1, p. 31-35, 2008.

BARDIN, L. Análise de conteúdo. Lisboa: Edições 70, 1979.

CEARÁ (Estado). Secretaria da Saúde do Estado. Geoportal de Informações da Saúde. Fortaleza: Secretaria da Saúde do Estado, 2011.Disponível em: <http://geolivre.saude.ce.gov.br>. Acesso em: 19 out. 2011.

CECCIM, R. B.; ARMANI, T. B.; ROCHA, C. F. O que dizem a legislação e o controle social em saúde sobre a formação de recursos humanos e o papel dos gestores públicos, no Brasil. Ciência \& Saúde Coletiva, Rio de Janeiro, v. 7, n. 2, p. 373-383, 2002.

DEJOURS, C. A loucura do trabalho. São Paulo: Cortez Editora, 1992.

DI MARTINO, V.; CORLETT, N. Work organization and ergonomics. Geneve: ILO, 1998.

FALZON, P. Natureza, objetivos e conhecimentos da ergonomia. In: 2007. p. 3-20. . Ergonomia. São Paulo: Blucher,

FORTALEZA. Prefeitura Municipal. Portal da Prefeitura de Fortaleza. Fortaleza: Prefeitura 
Municipal, 2011. Disponível em: <http://www. fortaleza.ce.gov.br>. Acesso em: 19 out. 2011.

GIL, C. R. R. Formação de recursos humanos em saúde da família: paradoxos e perspectivas. Cadernos de Saúde Pública, Rio de Janeiro, v. 21, n. 2, p. 490-498, 2005.

GRIFFITHS, P.; MABEN, J.; MURRELLS, T.

Organisational quality, nurse staffing and the quality of chronic disease management in primary care: observational study using routinely collected data. International Journal of Nursing Studies, Elmsford, v. 48, n. 10, p. 1199-1210, 2011. http://dx.doi. org/10.1016/j.ijnurstu.2011.03.011. PMid:21571273.

GUIMARÃES, R. M. et al. Fatores ergonômicos de risco e de proteção contra acidentes de trabalho: um estudo caso-controle. Revista Brasileira de Epidemiologia, São Paulo, v. 8, n. 3, p. 282-294, 2005.

MARQUES, R. M.; MENDES, A. Atenção Básica e Programa de Saúde da Família (PSF): novos rumos para a política de saúde e seu financiamento? Ciência \& Saúde Coletiva, Rio de Janeiro, v. 8, n. 2, p. 403-415, 2003.

MEDEIROS, S. M.; ROCHA, S. M. M. Considerações sobre a terceira revolução industrial e a força de trabalho em saúde em Natal. Ciência \& Saúde Coletiva, Rio de Janeiro, v. 9, n. 2, p. 399-409, 2004.

MUNTANER, C. et al. County and organizational predictors of depression symptoms among lowincome nursing assistants in the USA. Social Science \& Medicine, Oxford, v. 63, n. 6, p. 1454-1465, 2006. http://dx.doi.org/10.1016/j.socscimed.2006.03.042. PMid:16765496.
PEDUZI, M. et al. Qualidade no desempenho de técnicas dos trabalhadores de enfermagem de nível médio. Revista de Saúde Pública, São Paulo, v. 40, n. 5, p. 843-850, 2006.

PEREIRA, M. P. B.; BARCELLOS, C. O território no Programa de Saúde da Família. Hygeia, Uberlândia, v. 2, n. 2, p. 47-55, 2006.

PEREIRA, I. B.; LIMA, J. C. F. Educação profissional em saúde. In . (Org.). Dicionário da Educação Profissional em Saúde. Rio de Janeiro: FIOCRUZ, 2008. p. 126-133.

SARACENO, B.; ASIOLI, F.; TOGNONI, G. Manual de saúde mental: guia básico para atenção primária. São Paulo: Hucitec, 1997.

STACCIARINI, J. M. R.; TRÓCCOLI, B. T. O estresse na atividade ocupacional do enfermeiro. Revista Latino-Americana de Enfermagem, Ribeirão Preto, v. 9, n. 2, p. 17-25, 2001.

TAVEIRA, Z. Z. Precarização dos vínculos de trabalho na Estratégia Saúde da Família: revisão de literatura. 2010. 30 f. Trabalho de Conclusão de Curso (Especialização em Atenção Básica em saúde da Família)-Universidade Federal de Minas Gerais, Belo Horizonte, 2010.

VIEIRA, M.; CHINELLI, F. Relação contemporânea entre trabalho, qualificação e reconhecimento: repercussões sobre os trabalhadores técnicos do SUS. Ciência \& Saúde Coletiva, Rio de Janeiro, v. 18, n. 6, p. 1591-1600, 2013.

WISNER, A. O diagnóstico em ergonomia ou a escolha dos modelos operativos em situação real de trabalho. In: CASTILLO, J. J.; VILLENA, J. (Org.) Ergonomia. Lisboa: Dinalivros, 2005. p. 79-108. 